(c) American Dairy Science Association, 2006.

\title{
Major Advances Associated with Reproduction in Dairy Cattle
}

\author{
K. Moore and W. W. Thatcher ${ }^{1}$ \\ Department of Animal Sciences, University of Florida, Gainesville, 32611-0910
}

\begin{abstract}
The purpose of this overview is to review some of the major advances in reproductive technologies, and how they may be applied to meet the challenge of enhancing reproductive efficiency in the high-producing dairy cow of the 21st century. The current population of highproducing dairy cows is considered to be subfertile, as characterized by low pregnancy rates and high rates of embryonic mortality. Coordinated systems of reproductive management have been developed based upon a thorough understanding of the endocrine, cellular, and molecular factors controlling ovarian and uterine function. These systems will partially restore herd reproductive performance. Advances in other reproductive technologies offer possibilities for wider use of superior germplasm. Technologies such as sexed semen, cloning, transgenesis, and preimplantation genetic diagnosis offer the potential to enhance the influence of superior animals on production of food for human consumption. However, at this time, additional research is needed to counteract the higher rates of embryonic and fetal mortality associated with some of these technologies. Furthermore, use of genomics, proteomics, and bioinformatics in the study of reproduction will undoubtedly provide investigators with a greater understanding of the limitations to efficient reproductive processes in the subfertile lactating dairy cow.
\end{abstract}

Key words: biotechnology, hormones, ovary-uterus, embryo

\section{INTRODUCTION}

In the 75th anniversary issue of the Journal of Dairy Science in 1981, Jack Britt and coworkers encapsulated the technological advances that had led to major advancements in reproductive biology. Indeed, the arsenal of new tools provided the means for us to better understand the reproductive processes in dairy cattle. During the subsequent $25 \mathrm{yr}$, continued genetic progress for milk production coupled with nutritional management

Received September 16, 2004.

Accepted October 25, 2004.

${ }^{1}$ Corresponding author: thatcher@animal.ufl.edu of high-producing dairy cows has led to an antagonism between high milk production and fertility, in which reproductive efficiency of dairy herds has plummeted. The purpose of this overview is to review some of the major advances in reproductive technology, and how they may be applied to meet the challenge of enhancing reproductive efficiency in the high-producing dairy cow of the 21 st century.

\section{ADVANCES IN PHYSIOLOGY AND ENDOCRINOLOGY OF REPRODUCTION}

\section{Follicle Development Coordinated with Corpus Luteum Regression During the Estrous Cycle}

A major advancement in our understanding of ovarian follicular development occurred with the use of repeated ultrasound imaging. This permitted investigators to monitor dynamics of follicular development on a day-to-day basis in the same animal without compromising the ovarian and endocrine status of the cow. Recurring large ovulatory-sized follicles develop in a wave with a cohort of antral follicles that are all recruited in a synchronized manner in response to an FSH surge (Figure 1). Each wave is comprised of successive phases referred to as selection, deviation, dominance, and atresia. Follicular recruitment occurs every 8 to 10 d with cows generally having either 2 or 3 follicular waves during an estrous cycle. Within a wave of FSHrecruited follicles, one follicle is selected and undergoes deviation at approximately $8.5 \mathrm{~mm}$ in size (Figure 1). It continues to grow in a linear manner, while subordinate follicles of the wave cease to grow and undergo atresia. Consequently, this dominant follicle blocks recruitment of the next wave until it either undergoes atresia in a high progesterone environment (i.e., at midcycle) or undergoes spontaneous ovulation in a low progesterone environment following regression of the corpus luteum $(\mathbf{C L})$.

Understanding the mechanisms of control of these recurring follicular waves is of paramount importance for the development of optimal systems to control fertility in dairy cattle. Ovulation of fertile follicles for insemination, superovulation, and understanding how nutritional management of the high-producing dairy cow 


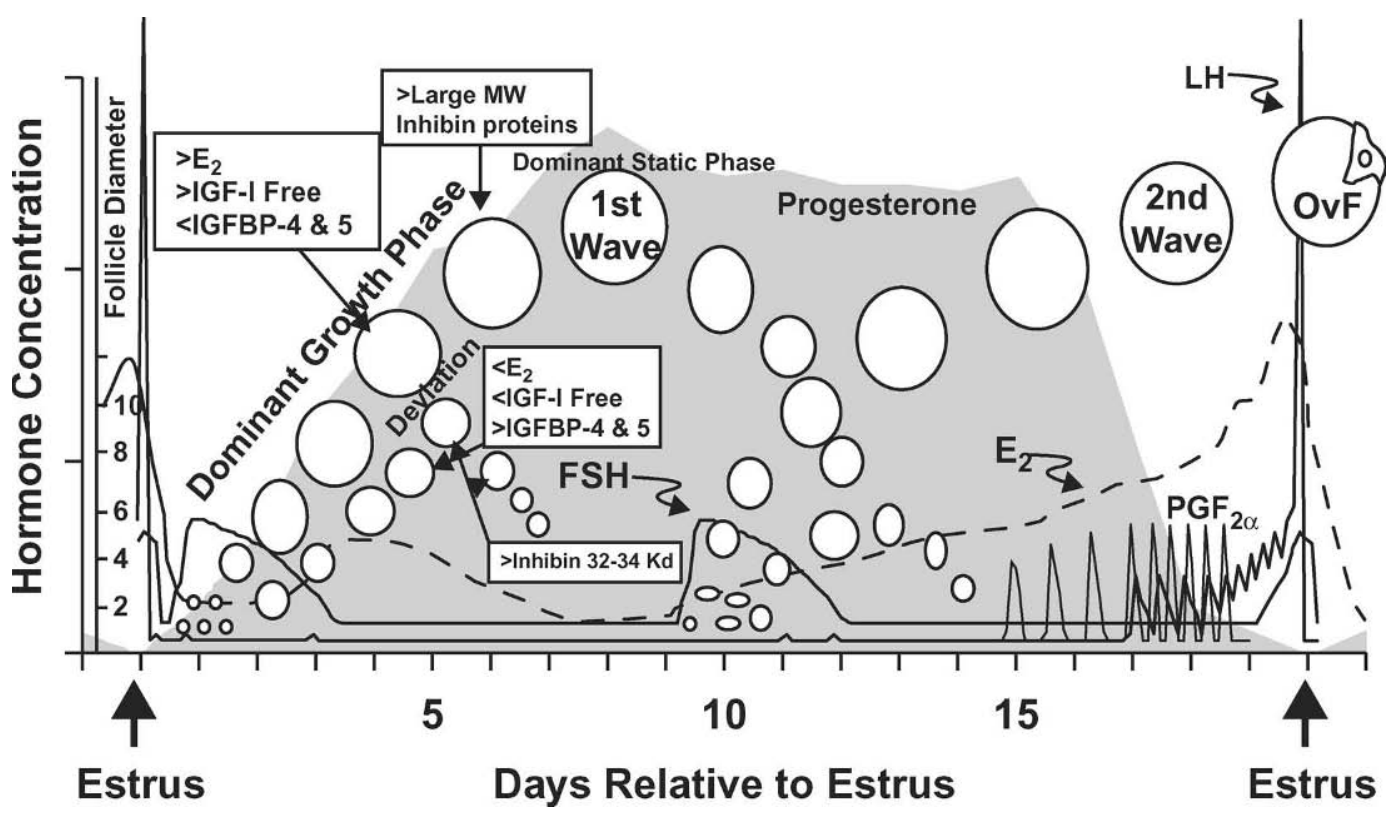

Figure 1. Ovarian follicular and corpus luteum development correlated with endocrine changes during the bovine estrous cycle. $\mathrm{E}_{2}=$ Estradiol; IGFBP-4 and $-5=$ insulin-like growth factor binding proteins 4 and 5 ; OvF = ovulatory follicle, OvF.

may affect fertility all depend on understanding follicle development. The first wave of follicle development, which emerges early in the estrous cycle, has become the experimental model of choice in elucidating the mechanisms controlling follicular waves because it is FSH-induced in a very precise and predictable manner following ovulation of a preovulatory follicle. The laboratories of J. Fortune, J. Ireland, and M. Mihm have delineated differences between the emerging dominant and subordinate follicles. At the time of expected deviation, the follicle that is selected as the dominant follicle has a higher concentration of estradiol in follicular fluid and a greater concentration of free insulin-like growth factor (IGF)-I that contributes to the estrogenic potential of the follicle (Figure 1). The concentration of free IGF-I is controlled by the local balance of IGF-binding proteins (i.e., IGFBP-4 and IGFBP-5) and protease activities that degrade IGFBP-4 and -5 . The IGF-binding proteins prevent IGF-I from binding to its receptor. This prevents activation of the signal transduction system that would have led to an increase in estradiol secretion. This is counteracted by activation of IGFBP proteases that permit IGF-I to bind to its receptor. Indeed, proteolysis of IGFBP-4 and -5 is greatest in the largest follicle both before and at the time of expected deviation within the first wave. Consequently, relative abundances of IGFBP-4 and -5 are reduced in the same follicles and concentrations of IGF-I are at their highest. As a consequence of these changes, IGF-I synergizes with FSH, leading to an estrogen-active dominant follicle.

In the early estrogenic follicle (i.e., $\mathrm{d} 3$ of the wave), mRNAs for the FSH receptor and aromatase are elevated within the granulosa layer, and theca cells have increased abundances of LH receptor and $17 \alpha$-hydroxylase, an enzyme required for production of androgen precursors for estrogen biosynthesis. However, there is an absence of LH receptor mRNA within the granulosa cells. Dynamic changes are evident within the inhibin family in that dimeric inhibins (i.e., $>160 \mathrm{kDa}$ ) are elevated and the smaller (32- to $34-\mathrm{kDa}$ ) dimer of inhibin is low in estrogen-active follicles (Figure 1). However, in estrogen-inactive follicles, the smaller inhibin dimer increases and the larger molecular weight forms are reduced. The increased secretions of estradiol and ovarian inhibin reach the pituitary gland through the circulation and lead to a decrease in pituitary secretion of FSH. Lack of FSH prevents further growth of subordinate follicles, which are also nonestrogenic due to low concentrations of free IGF-I. Once the dominant follicle reaches $10 \mathrm{~mm}$ (i.e., after deviation), its granulosa cells begin to express LH receptors, and it can be induced to ovulate at approximately $12 \mathrm{~mm}$ in size. Continued growth and dominance of the dominant follicle beyond $10 \mathrm{~mm}$ appears to be dependent upon LH secretion. Eventually, in the absence of an increase in pulse frequency of $\mathrm{LH}$, the dominant follicle undergoes functional atresia that permits an increase in FSH secretion 
and recruitment of a new follicle wave. These events are repeated with each wave until spontaneous CL regression occurs due to pulsatile secretion of $\mathrm{PGF}_{2 \alpha}$ (i.e., luteolytic mechanism, to be discussed later). In the low progesterone environment following luteolysis, negative feedback on the pituitary is reduced and LH pulse frequency increases, leading to final development of the dominant follicle. At approximately 17 to $20 \mathrm{~mm}$, the dominant follicle becomes fully estrogenic and induces a preovulatory LH surge that triggers ovulation.

\section{Control of the Estrous Cycle for Timed AI}

Current intensive commercial production systems for lactating dairy cows necessitate careful management of breeding, to the point of programming follicle waves, CL regression, and induction of ovulation. High levels of milk production, with associated increases in DM intake and metabolism of the lactating dairy cow have decreased efficiency of estrus detection and, unfortunately, reductions in pregnancy rate to inseminations at detected heats. Consequently, overall herd pregnancy rates have become severely reduced. This situation is not evident in heifers or cows that are not lactating.

Our current understanding of the mechanisms controlling the estrous cycle has led to the development of ovulatory control systems to implement timed insemination. These systems were developed utilizing pharmaceuticals that are comparable to the hormones or their analogues regulating normal ovarian function in the cow. Such approved pharmaceuticals offer the potential to mimic normal physiological processes from which investigators can further elucidate the mechanisms through which the lactational state compromises embryo survival. An additional factor in the United States limiting progress in development of these systems in lactating dairy cows has been the restricted availability of hormones that can be used in dairy cows that produce milk.

One of the early success stories is the use of $\mathrm{PGF}_{2 \alpha}$. The discovery in the early 1970 s that $\mathrm{PGF}_{2 \alpha}$ is the natural uterine luteolysin in cattle led J. Lauderdale to develop the use of exogenous $\mathrm{PGF}_{2 \alpha}$ to induce regression of the CL. In response to $\mathrm{PGF}_{2 \alpha}$, there is an intraluteal increase in blood flow that triggers initiation of the luteolytic cascade. The initial increase in blood flow appears to be due to a local induction of prostaglandin $\mathrm{H}$ synthase (PGHS)-2 within the CL that leads to the synthesis of vasodilatory substances such as prostacyclin $\left(\mathrm{PGI}_{2}\right)$. These vasodilatory-induced changes lead to local release of endothelin-1, angiotensin II, and atrial natriuretic peptide that collectively cause a de- crease in intraluteal blood flow and initiation of the luteolytic cascade resulting in decreased progesterone secretion.

Injections of $\mathrm{PGF}_{2 \alpha}$ to regress the CL are successful after d 5 of the estrous cycle. It also is evident that considerable variance exists as to when estrus will occur during the responsive diestrus period. The shortest interval to estrus (i.e., 2 to $3 \mathrm{~d}$ ) occurs when $\mathrm{PGF}_{2 \alpha}$ is given between d 7 and 9 or $\mathrm{d} 14$ and 16 of the estrous cycle, and longer intervals (i.e., 4 to $7 \mathrm{~d}$ ) occur between $\mathrm{d} 10$ and 12 of the cycle. The timing of $\mathrm{PGF}_{2 \alpha}$ injection relative to the stage of the follicular wave, which is usually unknown under most practical conditions, causes the variation in response. Injection of $\mathrm{PGF}_{2 \alpha}$ in the presence of a dominant, estrogen-active follicle, for example at $d 7$ of the cycle, results in an earlier occurrence of estrus than an injection given at d 11 (Figure 1). At d 11, the second-wave follicle is being selected and approximately $7 \mathrm{~d}$ is needed for the development of a new dominant follicle and estrus. Early strategies to synchronize estrus with $\mathrm{PGF}_{2 \alpha}$ injections were predicated on 2 consecutive injections given $11 \mathrm{~d}$ (i.e., heifers) or $14 \mathrm{~d}$ (i.e., lactating cows) apart. These 2 strategies were to ensure that a high proportion of animals would undergo CL regression at the second $\mathrm{PGF}_{2 \alpha}$ injection and have a higher synchronization rate of estrus. However, the variation in occurrence of estrus following the second injection of $\mathrm{PGF}_{2 \alpha}$ was not sufficiently precise to permit a timed insemination without detection of estrus.

Based upon understanding of normal follicular dynamics during the estrous cycle, it became clear that follicular synchronization should be coupled with induced regression of the CL to better control the precision in occurrence of estrus. The GnRH-induced release of $\mathrm{LH}$ causes ovulation or luteinization of dominant follicles $>10 \mathrm{~mm}$. The GnRH-induced turnover of the dominant follicle leads to recruitment of a new follicular wave, such that a new mature dominant follicle is present $7 \mathrm{~d}$ later, when one could induce regression of the original and/or GnRH-induced CL and improve the precision of induced heats. Such a programmed sequence is the basis of a timed insemination program called Ovsynch (Figure 2), in which a primary $\mathrm{GnRH}$ injection is given at some predetermined time after calving, followed by $\mathrm{PGF}_{2 \alpha} 7 \mathrm{~d}$ later. An additional injection of $\mathrm{GnRH}$ is given $48 \mathrm{~h}$ after injection of $\mathrm{PGF}_{2 \alpha}$. Timed AI should occur 12 to $16 \mathrm{~h}$ after injection of $\mathrm{GnRH}$, which would be followed by a synchronized ovulation at $28 \mathrm{~h}$ after GnRH.

The ability of the first GnRH injection to induce follicle turnover is dependent upon inducing ovulation of a dominant follicle. For example, if the first injection is 


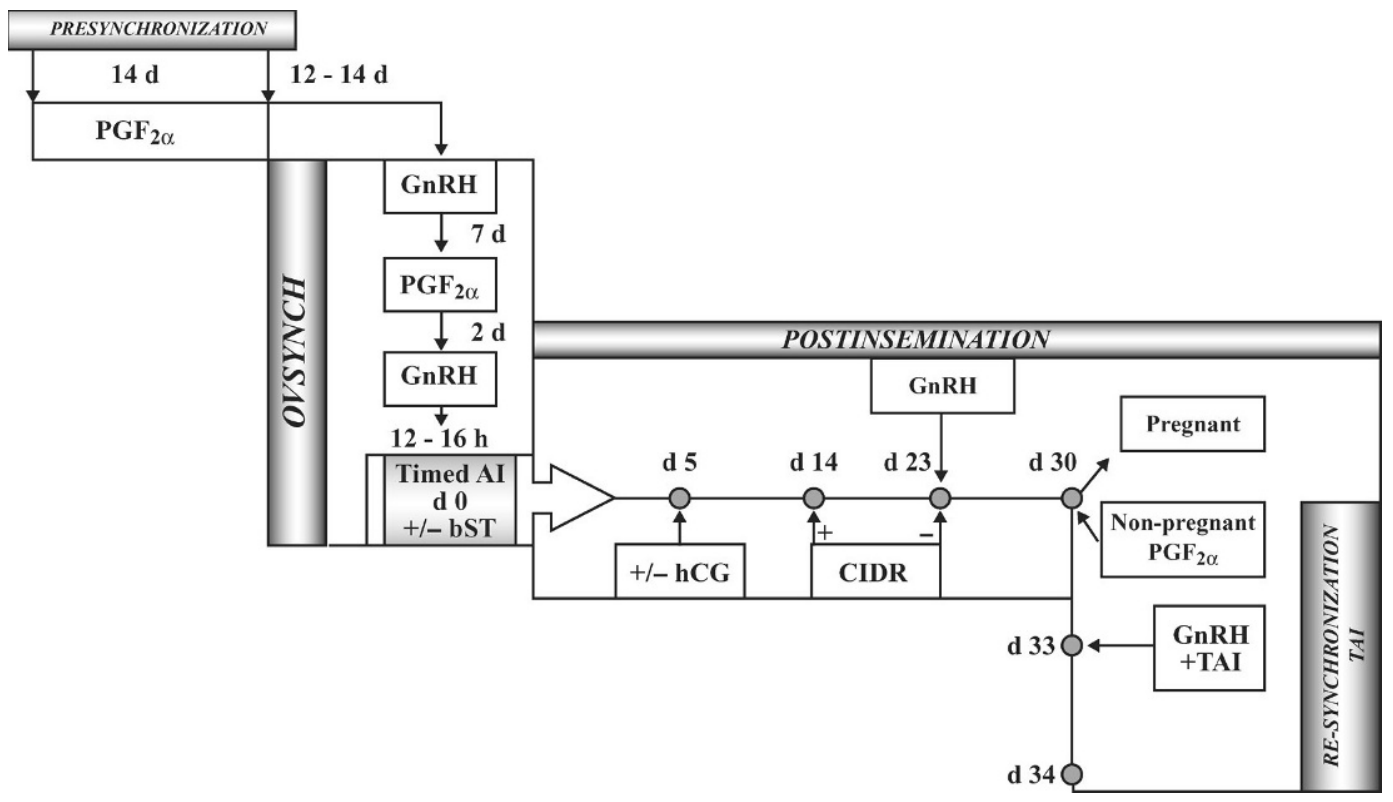

Figure 2. Reproductive management alternatives to improve reproductive performance of lactating dairy cows with the use of presynchronization, Ovsynch for timed artificial insemination (TAI), postinsemination endocrine treatments, and resynchronization for TAI. Endocrine treatments involve injection of bovine somatotropin (bST) at TAI and injection of human chorionic gonadotropin (hCG) at d 5 after TAI. Resynchronization of nonpregnant cows involves the insertion of an intravaginal progesterone device (CIDR) between $\mathrm{d} 14$ and 23 after artificial insemination and injection of $\mathrm{GnRH}$ at $\mathrm{d} 23$ at the time of CIDR withdrawal. Cows diagnosed nonpregnant at $\mathrm{d} 30$ receive an injection of $\mathrm{PGF}_{2 \alpha}$, and on $\mathrm{d} 33$ are injected with $\mathrm{GnRH}$ and concurrently inseminated.

during the metestrus stage of the cycle, a new follicle will not be induced and the ovulatory follicle at the second injection of $\mathrm{GnRH}$ is an aged follicle with a lower fertility to timed insemination. This has led to the development of a PreSynch/Ovsynch program in which 2 injections of $\mathrm{PGF}_{2 \alpha}$ are given $14 \mathrm{~d}$ apart, and the $\mathrm{Ov}$ synch program is started 12 to $14 \mathrm{~d}$ after the second $\mathrm{PGF}_{2 \alpha}$ injection of the presynchronization phase (Figure 2). If cows express estrus between $\mathrm{d} 3$ to 7 after the second injection of $\mathrm{PGF}_{2 \alpha}$, they will be between $\mathrm{d} 5$ to 11 of the estrous cycle when Ovsynch is started. Therefore, approximately $80 \%$ of the cows should have a follicle that ovulates to the first GnRH. Furthermore, all cows should have a functional CL during the interval between $\mathrm{GnRH}$ and $\mathrm{PGF}_{2 \alpha}$ injections that would reduce the occurrence of premature ovulations before the second injection of GnRH. This follicular synchronization scheme increases the probability that a "fresh" follicle is ovulated, following the second injection of $\mathrm{GnRH}$, and should lead to adequate CL development for maintenance of pregnancy.

More recently, an intravaginal device for the release of progesterone (CIDR) has become available for use in lactating dairy cows. This is an additional tool available for synchronization. In lactating dairy cows, the CIDR device can be inserted at the time of the first GnRH injection and removed when $\mathrm{PGF}_{2 \alpha}$ is injected as part of the Ovsynch program. This prevents premature occurrence of estrus before the ovulatory injection of GnRH in cows that regress their CL during the first 7 $\mathrm{d}$ of the Ovsynch protocol, and may induce cyclic activity in anovulatory cows that are treated with the Ovsynch program. Additional uses of the CIDR device as a presynchronization tool to ensure follicular synchronization or ovulation to the subsequent Ovsynch program, and resynchronization of estrus in cows that do not conceive to first service (Figure 2) warrant investigation.

It is clear that lactating dairy cows have suboptimal concentrations of both progesterone and estradiol due to liver metabolism associated with high DM intakes. Timed AI programs that include exogenous estradiol (e.g., estradiol cypionate given $24 \mathrm{~h}$ after $\mathrm{PGF}_{2 \alpha}$ ) are successful in inducing occurrence of estrus and actually increase conception rates to a timed insemination. Even though estradiol concentrations are considered subfertile in lactating dairy cows, the perception of consumers is that exogenous administration of estrogens to lactating dairy cows is harmful to the food supply. This perception has inhibited pharmaceutical companies from going through the potential governmental approval process for clearance of estrogens for such a use in North America. 


\section{Occurrence of Embryonic Death and Strategies to Improve Embryo Survival}

In spite of advancements in reproductive biology and the array of techniques available to control reproductive processes, herd reproductive efficiency continues to decline in lactating dairy cows. Various factors associated with programmed management of the estrous cycle for timed insemination have been identified that can contribute to poor fertility. These factors include ovulation of persistent or aged follicles, ovulation of small-sized preovulatory follicles, shortened pro-estrous period, inadequate progesterone exposure during the synchronization period, and luteal insufficiency following an induced ovulation. In addition, other factors appear to predispose the lactating dairy cow to a subfertility syndrome.

J. Santos and coworkers concluded that lower fertility of lactating dairy cows appears to be due to both a lower fertilization rate $(\sim 76 \%)$ and reduced embryo viability of these early embryos (i.e., $20 \%$ are not viable) compounded with greater early embryonic (i.e., $\sim 28 \mathrm{~d} ; 20 \%$ ) and late embryonic losses (i.e., 24 to $42 \mathrm{~d} ; 12.5 \%$ ). Total losses from fertilization to birth are up to $60 \%$ with a final conception rate at birth of $28 \%$. These total losses appear to be associated with lactation because similar rates are not seen in heifers or multiparous cows that are nonlactating. However, within populations of lactating cows, milk production per se is not a risk factor for increased pregnancy losses. Higher producing herds may be better managed regarding nutrition, health, and reproduction such that milk production associations are difficult to detect. Increased milk yield is accompanied by an increase in both feed intake and overall metabolic rate such that concentrations of estradiol and progesterone are decreased. Such alterations in steroid balance may reduce early embryonic development and warrant further investigation.

Lactating dairy cows are extremely sensitive to heat stress such that the oocyte on the day of estrus and the developing embryo during the first 3 cleavage divisions are heat-sensitive, resulting in lower fertilization rates and impaired embryo development. Transfer of in vivoproduced embryos from cows exposed to thermoneutral temperatures can increase pregnancy rate in heatstressed recipients. In order for this technology to be exploited in a cost-efficient manner, in vitro production and storage of embryos via in vitro maturation, fertilization, culture, and freezing needs to be implemented. However, proper development of the embryo in culture and subsequent fertility of these frozen embryos needs to be improved before embryo transfer strategies are able to offer producers the alternative of embryo transfer to bypass early embryo losses induced by heat stress.
In subtropical, tropical, and arid areas of the world, heat abatement facilities are essential to improve reproductive and milk production responses during seasonal periods of thermal stress.

It is well recognized that health disorders at parturition (e.g., dystocia, retained fetal membranes, milk fever) predispose cows to a lower level of fertility at the time selected for breeding. Indeed, incidence of metritis and subclinical endometritis in the prebreeding postpartum period reduces subsequent pregnancy rate in lactating dairy cows. Such findings emphasize the importance of optimizing nutritional and health statuses of cows during the periparturient and postpartum periods at a time when immune function is compromised in early lactation. Likewise, cows experiencing clinical mastitis events are at increased risk of having both reduced conception rates and increased fetal losses. Integration of nutritional and herd health programs will be a major area of research emphasis to improve reproductive efficiency of lactating dairy cows.

Effects of the last trimester of pregnancy, negative energy balance during the postpartum period, and elevated body temperatures (e.g., in response to thermal stress) are likely to impair the interaction between the oocyte and granulosa cells within the follicle, thus impairing fertility of the oocyte and contributing to inefficiencies in embryo development and embryo losses. This area warrants intensive investigation because possible effects on the follicular hierarchy may contribute to the duration of reduced fertility during the postpartum period and the extended period of reduced fertility following the seasonal heat-stress period. A period may be required for development of fertile follicles from smaller follicular classes that were not damaged by these physiological or physical states.

Several developments have improved reproductive performance of lactating dairy cows. Supplemental progesterone before d 6 after AI has increased pregnancy rates. Likewise, induction of an accessory CL with injection of human chorionic gonadotropin (hCG) at $\mathrm{d} 5$ after AI (Figure 2) has increased pregnancy rate, with cows that are losing body condition being the most responsive. Strategies to increase CL development and/or earlier synchronized increases in progesterone are likely to advance embryo development and enhance subsequent secretion of the antiluteolytic signal (i.e., interferon- $\tau$ ) responsible for maintenance of pregnancy. At approximately $17 \mathrm{~d}$ after estrus, interferon- $\tau$ produced by mononuclear cells of the trophectoderm can extend life span of the CL. Interferon- $\tau$ attenuates endometrial expression of estradiol receptor- $\alpha$ and oxytocin receptors, as well as causing a possible alteration in the oxytocin postreceptor signal transduction system. Collectively, these responses lead to an inhibition in the pulsatile 
release of $\mathrm{PGF}_{2 \alpha}$ from the endometrium, which promotes maintenance of the CL, thus maintaining pregnancy.

Treating cows with bST has increased milk production. Furthermore, first treatment with bST at insemination in cows following the Ovsynch protocol (Figure 2) or upon estrus detection increases pregnancy rates and reduces late embryonic death between d 31 and 45 after insemination. Treatment with bST improves fertilization rate, accelerates embryo development, improves embryo quality, and increases conceptus length at the time pregnancy is maintained. The overall improvement in fertility seems most evident following the first insemination after a designated waiting period following parturition. The impact of bST on the growth hormone and IGF-family (i.e., IGF-I and an array of different IGFBP) in the postpartum dairy cow and interactions with nutritional management programs (e.g., feeding of bypass fats) may offer new strategies to optimize reproductive performance of dairy cows. Early identification of nonpregnant cows to first insemination ( $\sim 23$ to $24 \mathrm{~d}$ ) through the timely synchronization of estrus with the use of an intravaginal progesterone insert (CIDR; Figure 2) and/or timed AI soon after an actual nonpregnancy diagnosis (e.g., 33 d) are additional strategies to improve reproductive performance. In the latter scenario of resynchronization (Figure 2), cows that recieved a CIDR device between $\mathrm{d} 14$ and 23 after insemination receive an injection of $\mathrm{GnRH}$ at the time of CIDR withdrawal to turn over the follicle on $d$ 23. Pregnancy is confirmed by ultrasound diagnosis 7 $\mathrm{d}$ later, at $\mathrm{d} 30$ after insemination. If the cow is nonpregnant then $\mathrm{PGF}_{2 \alpha}$ is injected, followed $3 \mathrm{~d}$ later with an injection of GnRH and a concurrent timed AI. Consequently, reinsemination occurred within $3 \mathrm{~d}$ after the nonpregnancy diagnosis or $\mathrm{d} 33$ after the prior service.

\section{ASSISTED REPRODUCTIVE TECHNOLOGIES}

Over the past $25 \mathrm{yr}$, artificial reproductive technologies (ART) have come to the forefront of reproductive research. Although many techniques are now available that promise to enhance reproductive performance, additional refinement and optimization allowing for subsequent embryo development and well being of the offspring are needed for these technologies to influence the dairy industry. Those with the most promise will be briefly summarized below.

\section{Superovulation and Embryo Transfer}

The advent of hormonal manipulation of the reproductive cycle of the cow, inducing multiple ovulations, coupled with AI, embryo collection, and embryo trans- fer, allows dairy producers to obtain multiple offspring from genetically superior females, by transferring their embryos into recipients of lesser genetic merit. Moreover, high genetic merit embryos can be frozen for later transfer or sale and will be discussed later. Nonsurgical embryo transfer procedures were first developed in 1964, and nonsurgical embryo collection procedures followed in 1972, making this technology even more feasible for the producer. These technologies have been commercially available since the 1980s. Recent efforts have incorporated timed embryo transfer, making this process even more manageable for the producer. Currently, costs associated with superovulation and embryo collection and storage are approximately $\$ 100 /$ embryo, and transfer costs average $\$ 25$ to $\$ 50 /$ transfer.

\section{In Vitro Production of Embryos}

In vitro manipulation of gametes for the production of embryos was first successful in mice in 1958 and in rabbits in 1959. At first, matured oocytes retrieved from the female were fertilized with sperm in the laboratory followed by transfer to a recipient mother. In 1981, the first live calf was produced by in vitro fertilization (IVF). Progress has been made in culture conditions, such that immature oocytes can now be retrieved and matured in vitro (IVM). The first live calf from an oocyte matured in vitro was reported in 1986. Three years later, Sirard and coworkers reported the first live calf produced by IVM/IVF and in vitro culture. These advances allowed for production of viable embryos from oocytes isolated from ovaries obtained at the slaughterhouse. The use of high genetic merit semen to fertilize oocytes retrieved from slaughterhouse ovaries is one method for generating large numbers of embryos with improved genetic potential.

Another major advance in this field is the nonsurgical technique of ovum pick-up (OPU). In 1988, Pieterse and colleagues showed that a transvaginal ultrasound probe with a needle guide could be used to aspirate oocytes from growing follicles in a live donor female. Oocytes are then matured and fertilized in vitro to produce viable embryos for transfer. These advances allow for oocyte retrieval from females at virtually any age or reproductive status, including prepubertal heifers and pregnant cows. This has the potential to substantially increase the lifetime productivity of high genetic merit females, and effectively reduces the generation interval.

Currently, 20 to $50 \%$ of oocytes fertilized in vitro develop into viable embryos depending on culture conditions, and are suitable for embryo transfer to synchronous recipients. However, conception rates for IVF embryos (30 to 40\%) are reduced compared with AI or 
embryos recovered nonsurgically from donor animals (50 to $70 \%$ ). Losses occur most frequently during the first $30 \mathrm{~d}$ of pregnancy, but can also occur throughout gestation. Moreover, some in vitro-produced offspring have prolonged gestation and increased birth weights (8 to $50 \%$ larger), which is attributed to large offspring syndrome (LOS), and a cesarean section is often required. These problems suggest that in vitro culture conditions are still inferior and need additional improvements to achieve developmental rates similar to that of in vivo-produced embryos. Furthermore, the poorer fertility of IVF embryos is exacerbated by their poor freezability as measured by reduced pregnancy rates post-thaw compared with fresh IVF embryos.

\section{Sexed Semen}

Altering the sex ratio in favor of heifer calves would be a great advantage for the dairy industry for producing replacement heifers. Until recently, the only option was to sex embryos. However, in 1987, Larry Johnson at the USDA introduced a method to sort sperm based on DNA content. Using a DNA-binding fluorescent dye (Hoechst 33342), sperm are stained and sorted on a fluorescence-activated cell sorter (FACS; Figure 3). The bovine X chromosome-bearing sperm contain 3.8\% more DNA than do Y-bearing sperm, allowing their separation. The technology is now commercially available through XY Inc., based in Fort Collins, CO, which has licensed the technology for cattle semen to Inguran in Texas and TransOva Genetics in Iowa.

Currently, there are 2 drawbacks associated with the sexed semen technology. First, it is a very slow process, producing only 150 to 200 straws of sexed semen per machine per day. To put that into perspective, US dairymen use almost 44,000 straws of semen each day. Additionally, many sperm are damaged in the sorting process and $70 \%$ of the sperm fail to be sorted due to damage or nondistinction, making this technology more costly for the producer. The second problem with sexed semen is lowered conception rates. Conception rates in virgin heifers with sexed semen average $35 \%$ vs. $55 \%$ for unsexed semen; however, the technology is $95 \%$ effective at producing the desired sex.

Strategies for using sexed semen to improve efficiencies and cost effectiveness are being developed. One such strategy is to make first-service breeding with sexed semen followed up with use of unsexed semen on repeat breeding. This method has been shown to result in $\geq 62 \%$ female offspring at first calving. Another means for improving efficiencies with sexed semen is its use for in vitro fertilization programs. On average, it is recommended to use 2 million sexed sperm to inseminate a single heifer. In contrast, less than 100,000
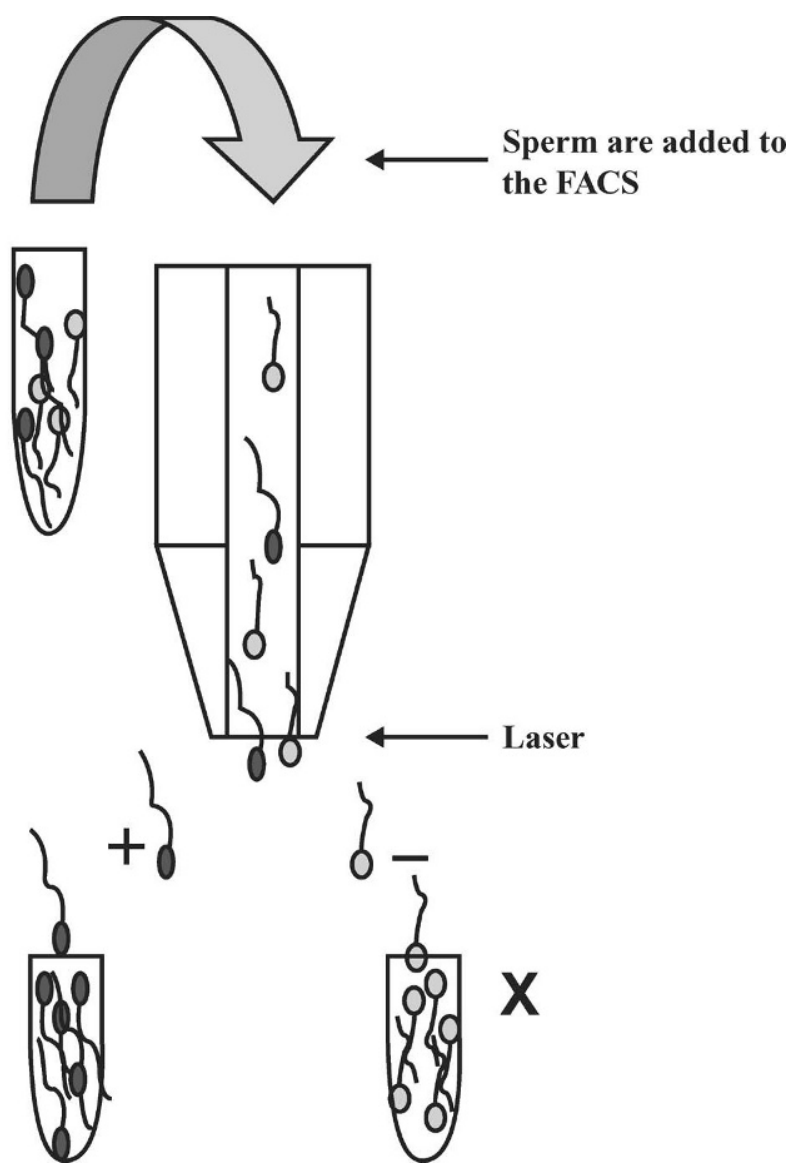

Figure 3. Schematic for sexing semen. Sperm are labeled with Hoechst 33342, a nucleic acid stain, and sorted on a fluorescence activated cell sorter (FACS). X-bearing sperm contain more DNA and thus fluoresce more, allowing them to be separated from Ybearing sperm.

sperm can effectively fertilize 100 oocytes in vitro, thus reducing the problem of speed and low sperm numbers following sexing. Further improvements will need to be implemented for this technology to gain widespread use in the dairy industry.

\section{Cloning}

Cloning is the production of a copy or copies of an individual, and occurs in animals either naturally or artificially, when an embryo is split to produce identical twins. The word "clone" has also been used to describe animals produced by nuclear transfer for the production of an unlimited number of genetically identical offspring. The first successes in cloning livestock were in 1986, when Steen Willadsen fused a cell from a 16cell embryo to an enucleated oocyte. This technology became commercially available for the dairy industry shortly thereafter, but was limited to the number of 


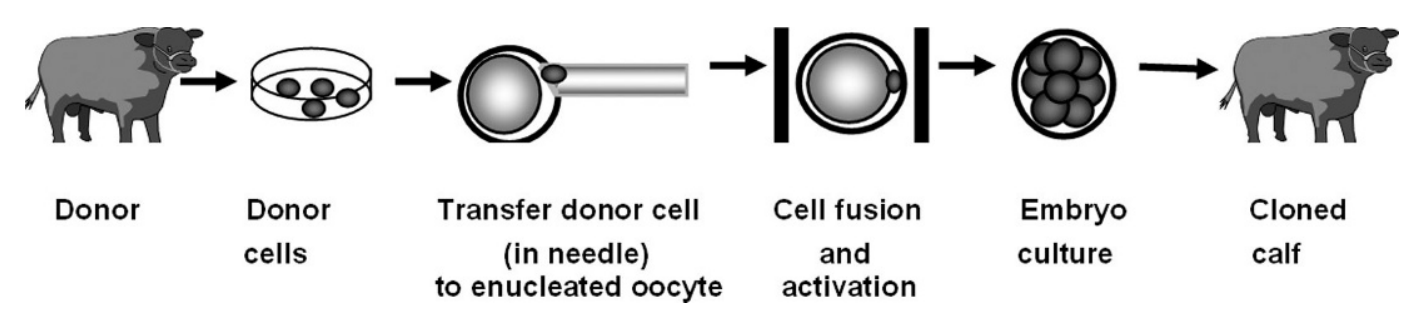

Figure 4. Overview of procedures for producing a cloned calf.

cells within an embryo, and the embryo did not have a proven phenotype. Moreover, the inherent inefficiency of the technology made it cost-prohibitive to most dairymen.

The biggest breakthrough in cloning came in 1996, when Ian Wilmut and colleagues produced Dolly the sheep by fusing a cultured adult somatic cell with an enucleated oocyte. Although still quite inefficient, cloning with adult cells offers the advantage of cloning genetically proven animals and having an unlimited supply of donor cells. Somatic cell cloning has now been successful for producing all livestock species, as well as many laboratory animals and pets.

The main application of cloning to the dairy industry is for expanding the use of genetically superior animals. Such animals of high merit, male or female, can be selected for cloning based on any desirable trait, including milk production, growth, feed efficiency, or disease resistance. Furthermore, the nutrition, reproduction, and health of cloned animals should be more easily managed because of animal uniformity. Nuclear transplantation has also been useful for propagating genetically superior individuals that are old, injured, or recently deceased. Moreover, cloning will become advantageous for producing genetically modified dairy cattle, by adding beneficial traits or removing less desirable ones, as discussed in the next section.

The cloning procedure involves removing the chromosomal DNA from mature oocytes and replacing it with a cell from the donor animal to be cloned (Figure 4). The donor cell is then fused with the enucleated oocyte and activated either chemically or with an electrical pulse to induce activation and reprogramming of the somatic cell genome to that of an embryonic genome. Reconstructed cloned embryos are then cultured for 6 to $9 \mathrm{~d}$ and viable embryos are transferred to synchronized recipients and carried to term to produce live cloned offspring.

Although cloning is commercially available, the technology is still quite inefficient and very costly. Inefficiencies stem from micromanipulation of oocytes and embryos and culture of donor cells and cloned embryos. On average, only $10 \%$ of cloned embryos transferred are carried to term (less than $1 \%$ of the cloned embryos originally constructed). This is due to the large number of abortions that occur throughout gestation. Furthermore, when pregnancies progress to term, gestation is usually extended and calves are born much larger than average due to LOS that leads to dystocia, with most animals requiring cesarean section. These large offspring often have postnatal weakness, hypoxia, hypoglycemia, metabolic acidosis, and hypothermia requiring immediate intensive care. Problems such as these hinder the wide use of cloning by the dairy industry.

Finally, a challenge of nuclear transfer is the potential loss of genetic diversity. Although unlimited numbers of identical cattle can be produced with cloning, it should not replace natural breeding. If it did, it could result in inbreeding and loss of genetic variation, which are not desirable. This same concern was addressed when AI was implemented commercially. Cloning is not predicted to have the same widespread use as AI, but producers are now aware of these potential problems, and with proper management of breeding schemes, problems such as these will not occur.

\section{Transgenesis}

Traditional methods for making genetic improvements by the dairy producer have been through pedigree analysis and genetic selection of seed stock. Although this will continue to be at the forefront, producers may soon see the fruits of new approaches for improving dairy cattle genetics. Transgenic technologies allow improvements not currently possible through traditional breeding schemes. Beneficial traits can be added from other species. As an example, it was recently shown that a bacterial gene could be expressed in the mammary gland that allowed resistance to certain strains of mastitis. Additionally, Brophy and colleagues improved milk quality by increasing casein production. This alteration increased milk solids available for sale and improved cheese production traits. Pharmaceutical companies have also taken an interest in the dairy cow as a biopharmaceutical production unit; a transgenic cow is produced that contains a gene for a particular 
drug that is only expressed in the milk. During lactation, the cow serves as a very efficient factory, producing large quantities of the drug in milk that can then be harvested and purified at a reduced price over traditional methods of making pharmaceuticals. These drugs are currently in clinical trials and will most likely be marketed within the next $5 \mathrm{yr}$.

The production of transgenic animals was first introduced in 1980 by Jon Gordon and colleagues. Copies of the foreign gene were injected into the pronucleus of the newly fertilized 1-cell mouse embryo. This same technology progressed to successful production of transgenic pigs, goats, sheep, and cattle; however, efficiencies are very low, often being less than $1 \%$. Moreover, this approach was mostly useful for the overproduction of a foreign gene. Although transgene overexpression is still the easiest approach, newer advances through cloning technology permit single gene insertions, deletions, or even modifications in gene sequence using gene targeting.

Genetic modifications of dairy cattle through transgenesis offer many benefits for improved animal health and production, yet inefficiencies and ethical considerations may hamper its acceptance. At best, less than $1 \%$ of transgenic embryos survive to term and of those, fewer than 50\% will express the transgene. One company, Genzyme, reports that with these inefficiencies along with all of the governmental regulations, it can cost up to $\$ 5$ million to produce one biopharmaceuticalproducing transgenic animal. Additionally, current public understanding and acceptance of genetically modified foods is poor. In order for this technology to have an impact on the dairy industry, efficiencies of transgenic embryo production and the public's perception of the science will have to improve substantially.

\section{PREIMPLANTATION GENETIC DIAGNOSTIC EMBRYO SCREENING}

Artificial reproductive technologies offer tremendous advantages for improving genetic selection for the dairy industry. Genetically elite embryos of the desired sex can be transferred to recipients; thus, increasing the number of genetically superior replacement animals available to the herd. However, these technologies are costly due to expenses associated with maintaining recipients that fail to become pregnant or abort during gestation. Currently, 45 to $75 \%$ of cattle embryos transferred result in pregnancy depending upon their origin (i.e., fresh, frozen, short-term cultured). Although these results are good, there are further reductions up to time of calving, resulting in maintenance expenses of nonpregnant recipient cows. Pregnancy and calving is further reduced if the embryos are produced in vitro

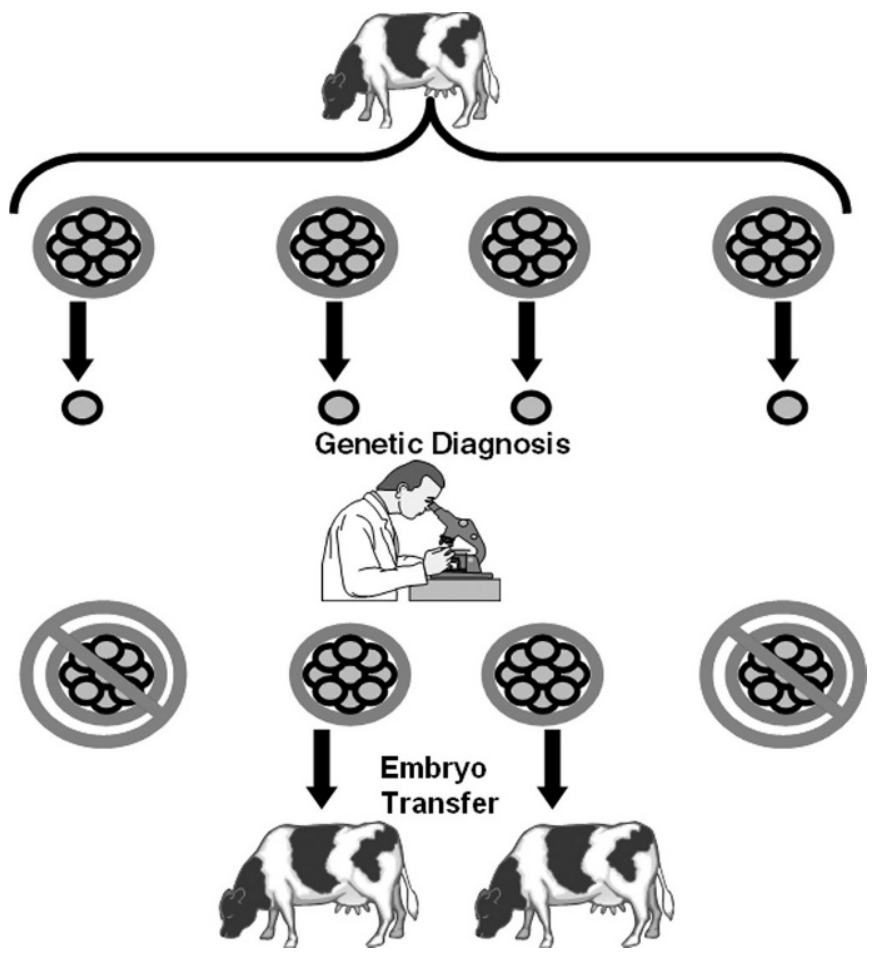

Figure 5. Preimplantation genetic diagnosis procedure. A single blastomere is removed from each embryo (biopsy) and analyzed by PCR, karyotyping, and fluorescence in situ hybridization. Embryos determined to be genetically normal are then transferred to synchronous recipients.

(IVP) or cloned, making these technologies less cost effective.

Preimplantation genetic diagnosis (PGD) is a newer technology that may provide much needed assistance toward reducing these costs. Although PGD was first developed in the late 1980s for use in identifying genetic defects in embryos produced by human fertility clinics, it has now been adapted for screening livestock embryos during the first few days of embryonic life before transfer. A single cell from a developing embryo is removed (blastomere biopsy) for genetic testing, whereas the embryo continues development in culture (Figure 5). The single cell can potentially be screened for an unlimited number of single gene traits or chromosomal abnormalities using approaches such as PCR, karyotyping, or fluorescence in situ hybridization (FISH). Using these techniques, embryos can be prescreened, allowing quick elimination of genetically abnormal embryos. Additionally, these procedures would even allow for selection of embryos with economically beneficial traits as they become identified through genome sequencing projects. Following PGD, selected embryos can be transferred to recipients, resulting in higher rates of pregnancy and survival to term, thus reducing producer expenses. 
Animal breeding strategies currently screen sires and dams for genetic abnormalities and often recommend avoiding use of germplasm from genetic lethal carrier animals. Bovine leukocyte adhesion deficiency (BLAD) and complex vertebral malformation $(\mathbf{C V M})$ are 2 such traits that currently plague the dairy industry. The PGD procedure would allow the continued use of valuable germplasm even from carrier animals, by screening embryos before transfer and discarding the few affected embryos. This would be beneficial to breeders that have semen banked on sires that have only recently been identified as carriers of a newly identified genetic trait, but that still have many beneficial traits that could be profited from in breeding schemes.

Preimplantation genetic diagnosis is still evolving as a tool for the livestock industry. Embryo sexing has been commercially available since the late 1980 s, and recent progress in the genome projects is identifying both beneficial and detrimental genes, allowing potential screening tools for the future. To date, however, there are very few tests commercially available for use by the dairy industry.

\section{Gamete Storage}

Freezing semen has garnered the greatest advances of the artificial reproductive technologies for the dairy industry to date. Although AI was being used by the dairy industry as early as the 1930 s, frozen semen was not available until the 1950 s. Since that time, different additives, cryoprotectants, and sperm concentrations have been studied to improve the survival and number of units that could be produced from an ejaculate. Two major advances have transpired in this field over the last 25 yr: sexing semen (see above) and freeze-drying sperm. The freeze-drying of sperm would be a great improvement in removing the need for liquid nitrogen storage. However, repeatable successes have only been demonstrated in mice at this time, and require microinjection of sperm into the oocytes. It is hoped that continued research will perfect this technology for use in cattle.

Cryopreservation of cattle embryos was first successful in 1973, but was very inefficient. Due to the size and complexity of the embryo, changes had to be made in freezing protocols involving slow cooling with cryoprotectants to subzero temperatures and slow warming at thawing to maintain embryo viability. Today, cattle embryos are most commonly frozen in $1.5 \mathrm{M}$ ethylene glycol, a cryoprotectant that allows for direct transfer into the recipient post-thaw. Additional improvements in viability are realized if embryos of higher quality are frozen, with grade- 1 embryos giving a 5 to $10 \%$ higher pregnancy rate following transfer. Vitrification is a newer method for rapidly freezing embryos that avoids crystal formation, placing the embryo in a "glass state," which should reduce damage from freezing. However, cryoprotectants for vitrification are used at much higher concentrations and can become toxic if not handled correctly. Moreover, this procedure requires additional equipment and time for rehydration upon thawing. Frozen embryos can now be exported, as long as the surrounding zona pellucida is intact and free of cumulus cells. A trypsin treatment has been instituted to remove or inactivate viruses, and thereby, decrease the possibility of disease transmission.

Cryopreservation of in vitro matured, fertilized, and cultured embryos or cloned embryos is still problematic, because survival after thawing is reduced. Current culture conditions impart changes in cytoplasm of in vitroproduced embryos resulting in reduced survival postthaw. Moreover, breaching the zona during micromanipulation is also known to have a negative effect on subsequent survival post-thaw. Future efforts to improve culture conditions, as well as modify freezing protocols, will be necessary to improve the viability of in vitro-manipulated embryos compared with that of their in vivo-produced counterparts.

Unfertilized oocytes are another resource with potential for cryopreservation. This technology is still in development. Matured oocytes are generally denuded of surrounding cumulus cells before freezing, whereas germinal vesicle stage oocytes are frozen intact. Currently, this method is only beginning to be researched for use in cattle. The process is very inefficient and will need further improvements before it can be a useful technology for the dairy industry.

Ovarian tissue cryopreservation is also a potential option for saving germplasm of valuable animals. This technology was first successful in rodents in the 1950s; however, it has not been adapted for use in livestock species at this time due to limitations in its usefulness and possibilities of tissue rejection upon transplantation. This technology is being explored more for women to save germplasm for transplantation after either chemotherapy or menopause.

The advent of somatic cell nuclear transfer has expanded the definition of gamete storage. Now, it is believed that any somatic cell can serve as the nuclear donor in the cloning process. As such, tissue biopsies are being taken and cell lines derived from valuable donor animals and banked for future use in cloning. Questions still unanswered include what is the best cell type to harvest and what is the best method of propagation to ensure the best results in the cloning process. Answers to these questions will allow producers to bank cells ensuring the greatest likelihood of producing viable, healthy calves in the future. 


\section{GENOMICS, PROTEOMICS, AND BIOINFORMATICS}

Over the past quarter century, a lot has been learned about the biomolecular make-up of living organisms. The term genomics refers to the study of nucleic acids, in particular DNA and RNA, within a particular organism. Proteomics is the study of the complete complement of proteins, their localization, modifications, and functions within an organism. The explosive growth of information generated using these tools from various species and comparison across species has required the expansion of a field to compile and analyze these data and is referred to as bioinformatics.

\section{Genomics}

In 1977 , the ability to sequence nucleic acids became available, but it was not until the mid-1980s that the human genome sequencing project was proposed. This colossal endeavor was finally completed and published in 2001. Since then, genomes from several other species have been sequenced, including the mouse, fruit fly, nematode, several plants, and many bacteria. In 2003, the USDA, in collaboration with NIH, announced the Bovine Genome Sequencing Project, a $\$ 53$ billion worldwide endeavor to complete the sequencing of the cattle genome (for more information on the project see www.hgsc.bcm.tmc.edu/projects/bovine). There are 3 billion nucleotides estimated to be in the bovine genome with roughly $1 \%$ coding for functional genes, of which $40 \%$ or more have unknown functions. The high degree of conservation of genetic sequences across different species is providing valuable comparisons of genomic sequences to help in the discovery of genes and to map their location to bovine chromosomes.

Gene discovery tells us nothing of gene function. However, searching databases from other species is helping to predict gene function, particularly for single gene traits. Other methods are helping us to identify functional roles of genes and include gene chips or microarrays, gene knockouts, and gene knockdowns. Microarrays are nylon or glass slides ("chips") that are spotted with partial gene coding sequences. Chips are incubated with fluorescently tagged complementary DNA (cDNA) from tissues of interest to determine what genes are being expressed (Figure 6). For example, uterine tissue gene expression can be compared between lactating and nonlactating dairy cows at any particular time of interest.

Knockouts are genetically engineered mutations, usually produced in mice, which delete a gene. The knockout mouse can be studied and compared with a normal or "wild type" mouse to determine what is not occurring or is occurring abnormally in the knockout mouse, and thus allows speculation as to what that

\section{Control} cells

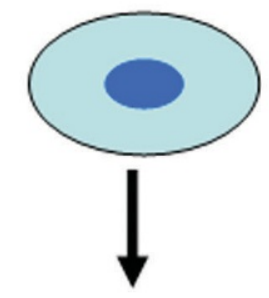

Total RNA

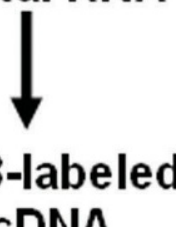

cDNA

(Green)

\section{Treated \\ cells}

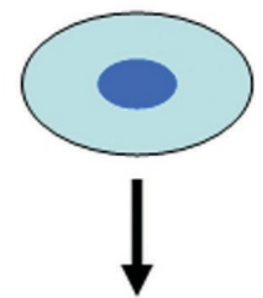

Total RNA

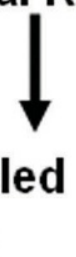

Cy5-labeled cDNA

(Red)

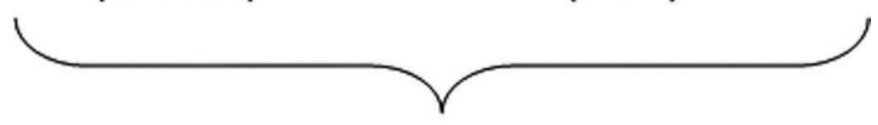

\section{Mix cDNAs, hybridize to chip, and scan differential coloration}

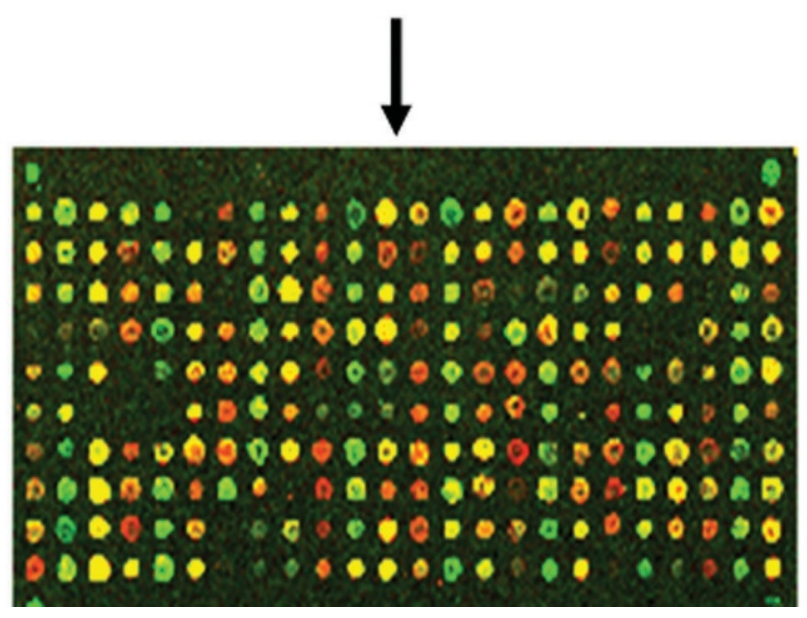

Figure 6. Double-dye microarray comparing 2 treatments. A ratio between treated and untreated is computed from differential coloration of the image to determine if the treated sample has higher, lower, similar, or no expression for each gene on the chip compared with the untreated sample (figure modified with permission from Schlecht and Primig, 2003). 
gene normally does. A good example applicable to the cattle industry is the knockout of the myostatin gene. It was determined that this gene regulated muscle development, because myostatin knockout mice had enlarged skeletal muscles. It was later shown that a natural mutation in the myostatin gene in cattle produced double-muscling. Knockdowns have a similar effect but do not require genetic modifications to produce the modified phenotype. Expression of the gene of interest is "knocked down" using an RNA interference strategy, resulting in the gene's message being degraded. All of these approaches are shedding additional information allowing localization of gene expression and gene function.

Sequencing the bovine genome and further advances in functional genomics promise great benefits to the dairy industry. As genes for production traits are identified, genetic selection strategies can be improved. One can envision making improvements in milk yields and milk fat and protein composition, or even improved herd health and food safety. Unfortunately, most traits are complex, brought about by the effects of several genes and environmental factors that are much more difficult to unravel. The daunting task of marker-assisted selection using quantitative trait loci (QTL) should be much improved with these newer technologies. As genes for production traits are identified, these tasks will be reduced to simply running a genetic test for the particular gene(s) of interest.

\section{Proteomics}

The analysis of the full complement of proteins within an organism-proteomics-is now gaining greater attention as technologies advance. This is much more complicated than genomics because proteins can be biochemically modified post-translation within the cell, creating multiple forms of a protein. Furthermore, proteins can bind to one another as subunits of a multimeric protein. These possibilities significantly increase the number of potential proteins within an organism to well above what would be predicted from the estimated 30,000 genes. Understanding how proteins function together in cellular pathways will help in the development of new therapeutic agents and provide new ways to diagnose and treat reproductive disorders.

\section{Bioinformatics}

The task of compiling mountains of data and mining valuable information from the arenas of genomics and proteomics is the field of bioinformatics. It will involve unraveling the complexities of genetic sequences, gene expression data, and protein localization and function information, to determine gene and protein functions within a particular cell, organ, or the whole animal. Computer science has quickly been merged with biological sciences to accomplish this task. A helpful introductory Web site on the topic can be found at www.geocities.com/bioinformaticsweb/. Databases and software are being developed that can properly store, sort, and make comparisons to make predictions as to the identity of new genes, their chromosomal locations, and possible protein structures and functions. Newer on the horizon is mapping gene and protein expression information within 3-dimensional structures, such as a developing fetus. Making such information easily available will allow the development of new drugs and vaccines for improving animal reproductive health.

\section{CONCLUSIONS}

Tremendous advances have been made for improving milk production, but have in turn, resulted in an overall decline in reproductive efficiency for the dairy industry. To combat this problem, research must focus on improvements in 3 main areas: the cow, the gametes, and the environment. Problems associated with the cow include inability to properly detect estrus, and altered hormone profiles resulting in low conception rates and increased early embryonic death. Coordinated systems of reproductive and nutritional management offer vehicles to improve herd reproductive performance. Advances in reproductive technologies offer wider use of germplasm. However, at this time, additional research is needed to counter the higher rates of embryonic and fetal mortality, and aberrant gene expression leading to LOS. Technologies associated with sexed semen, cloning, transgenesis, and PGD offer the potential to enhance the influence of superior animals on production of food for human consumption. Detailed studies of tissue and cell biology, utilizing the techniques of genomics, proteomics, and bioinformatics, will undoubtedly allow investigators to understand the limitations to efficient reproductive processes of the subfertile lactating dairy cow.

\section{ACKNOWLEDGMENTS}

This journal article was supported by Florida Agricultural Experimental Station.

\section{REFERENCES}

Britt, J. H., N. M. Cox, and J. S. Stevenson. 1981. Advances in reproduction in dairy cattle. J. Dairy Sci. 64:1378-1402.

Brophy, B., G. Smolenski, T. Wheeler, D. Wells, P. L'Huillier, and G. Laible. 2003. Cloned transgenic cattle produce milk with higher levels of $\beta$-casein and $\kappa$-casein. Nat. Biotechnol. 21:157-162. 
Burke, J. M., R. L. De la Sota, C. A. Risco, C. R. Staples, E. J.-P. Schmitt, and W. W. Thatcher. 1996. Evaluation of timed insemination using a gonadotropin-releasing hormone agonist in lactating dairy cows. J. Dairy Sci. 79:1385-1393.

Cerri, R. L. A., K. N. Galvao, S. O. Juchen, R. C. Chebel, and J. E. P. Santos. 2003. Timed AI (TAI) with estradiol cypionate (ECP) or insemination at detected estrus in lactating dairy cows. J. Dairy Sci. 86(Suppl.1):181. (Abstr.)

Fields, M. J., R. S. Sand, and J. V. Yelich, eds. 2002. Factors affecting calf crop: Biotechnology of reproduction. CRC Press, Boca Raton, FL.

Foote, R. H. 2002. The history of artificial insemination: Selected notes and notables. J. Anim. Sci. 80(E. Suppl.):E22-E32.

Fortune, J. E., G. M. Rivera, and M. Y. Yang. 2004. Follicular development: The role of the follicular microenvironment in selection of the dominant follicle. Anim. Reprod. Sci. 82-83:109-126.

Ginther, O. J., M. A. Beg, D. R. Bergfelt, F. X. Donadeu, and K Lot. 2001. Follicle selection in monovular species. Biol. Reprod. 65:638-647.

Gordon, J. W., G. A. Scangos, D. J. Plotkin, J. A. Barbosa, and F. H. Ruddle. 1980. Genetic transformation of mouse embryos by microinjection of purified DNA. Proc. Natl. Acad. Sci. USA 77:7380-7384.

Hansen, P. J., and J. Block. 2004. Towards an embryocentric world: The current and potential uses of embryo technologies in dairy production. Reprod. Fertil. Dev. 16:1-14.

Hasler, J. F. 2003. The current status and future of commercial embryo transfer in cattle. Anim. Reprod. Sci. 79:245-264.

Ireland, J. J., M. Mihm, E. Austin, M. G. Diskin, and J. F. Roche. 2000. Historical perspective of turnover of dominant follicles during the bovine estrous cycle: Key concepts, studies, advancements and terms. J. Dairy Sci. 83:1648-1658.

Johnson, L. A. 1995. Sex preselection by flow cytometric separation of $\mathrm{X}$ and $\mathrm{Y}$ chromosome-bearing sperm based on DNA difference: A review. Reprod. Fertil. Dev. 7:893-903.

Kerr, D. E., K. Plaut, A. J. Bramley, C. M. Williamson, A. J. Lax, K. Moore, K. D. Wells, and R. J. Wall. 2001. Lysostaphin expression in mammary glands confers protection against staphylococcal infection in transgenic mice. Nat. Biotechnol. 19:66-70.

Lauderdale, J. W., B. E. Seguin, J. N. Stellflug, J. R. Chenault, W. W. Thatcher, C. K. Vincent, and A. F. Loyancano. 1974. Fertility of cattle following $\mathrm{PGF}_{2 \alpha}$ injection. J. Anim. Sci. 38:964-967.

McPherron, A. C., A. M. Lawler, and S. J. Lee. 1997. Regulation of skeletal muscle mass in mice by a new TGF-beta superfamily member. Nature 387:83-90.

Mihm, M., and E. J. Austin. 2002. The final stages of dominant follicle selection in cattle. Domest. Anim. Endocrinol. 23:155-166.

Moore, K. 2002. Cloning and the Beef Cattle Industry. Pages 219229 in Factors affecting calf crop: Biotechnology of reproduction. M. J. Fields, R. S. Sand, and J. V. Yelich, ed. CRC Press, Boca Raton, FL.
Moore, K., and J. A. Piedrahita. 1999. Transgenic Animals. Pages 820-834 in Encyclopedia of Reproduction. Vol. 4. E. Knobil and J. D. Neill, ed. Academic Press, San Diego, CA.

Moreira, F., C. Orlandi, C. A. Risco, R. Mattos, F. Lopes, and W. W. Thatcher. 2001. Effects of pre-synchronization and bovine somatotropin on pregnancy rates to a timed artificial insemination protocol in lactating dairy cows. J. Dairy Sci. 84:1646-1659.

Pieterse, M. C., K. A. Kappen, T. A. M. Kruip, Y. A. Wurth, and M. A. M. Taverne. 1988. Aspiration of bovine oocytes during transvaginal ultrasound scanning of the ovaries. Theriogenology 30:751-762.

Pursley, J. R., P. M. Fricke, H. A. Garverick, D. J. Kesler, J. S. Ottobre, J. S. Stevenson, and M. C. Wiltbank. 1997. Reproductive management of lactating dairy cows using synchronization of ovulation. J. Dairy Sci. 80:301-306.

Roberts, R. M. 2002. National bovine genomics projects: Present status, future directions, and why they are important. Pages 165175 in Factors affecting calf crop: Biotechnology of reproduction. M. J. Fields, R. S. Sand, and J. V. Yelich, ed. CRC Press, Boca Raton, FL.

Schams, D., and B. Berisha. 2004. Regulation of corpus luteum function in cattle-An overview. Reprod. Domest. Anim. 39:241-251.

Schlecht, U., and M. Primig. 2003. Mining meiosis and gametogenesis with DNA microarrays. Reproduction 125:447-456.

Seidel, G. E. 2002. Sexing sperm for beef and dairy cattle breeding. Pages 281-286 in Factors affecting calf crop: Biotechnology of reproduction. M. J. Fields, R. S. Sand, and J. V. Yelich, ed. CRC Press, Boca Raton, FL.

Sirard, M. A. 1989. Practical aspects of in-vitro fertilization in cattle. J. Reprod. Fertil. Suppl. 38:127-134.

Thatcher, W. W., F. Moreira, J. E. P. Santos, R. C. Mattos, F. L. Lopes, S. M. Pancarci, and C. A. Risco. 2001. Effects of hormonal treatments on reproductive performance and embryo production. Theriogenology 55:75-89.

The Practice Committee of the American Society for Reproductive Medicine. 2004. Ovarian tissue and oocyte cryopreservation. Fertil. Steril. 82:993-998.

Vajta, G., P. Holm, M. Kuwayama, P. J. Booth, H. Jacobson, T. Greve, and H. Callesen. 1998. Open pulled straw (OPS) vitrification: A new way to reduce cryoinjuries of bovine ova and embryos. Mol. Reprod. Dev. 51:53-58.

Voelkel, S. A., and Y. X. Hu. 1992. Direct transfer of frozen-thawed bovine embryos. Theriogenology 37:23-37.

Wakayama, T., and R. Yanagimachi. 1998. Development of normal mice from oocytes injected with freeze-dried spermatozoa. Nat. Biotechnol. 16:639-641.

Willadsen, S. M. 1986. Nuclear transplantation in sheep embryos. Nature 320:63-65.

Wilmut, I., A. E. Schnieke, J. McWhir, A. J. Kind, and K. H. Campbell. 1997. Viable offspring derived from fetal and adult mammalian cells. Nature 385:810-813.

Young, L. E., K. D. Sinclair, and I. Wilmut. 1998. Large offspring syndrome in cattle and sheep. Rev. Reprod. 3:155-163. 